\title{
Perspectives on the use of aromatherapy from clinicians attending an integrative medicine continuing education event
}

\author{
Amy C. S. Pearson ${ }^{1 *}$ (D), Susanne M. Cutshall ${ }^{2}$, W. Michael Hooten ${ }^{3}$, Nancy J. Rodgers ${ }^{4}$, Brent A. Bauer ${ }^{4}$ and \\ Anjali Bhagra ${ }^{4}$
}

\begin{abstract}
Background: The use of essential oils is growing in the United States, but clinician attitudes, experience, and beliefs regarding their use have not previously been studied.

Methods: One hundred five of 106 clinician attendees (99.1\%) of an integrative medicine continuing education conference were surveyed using an audience response system to obtain baseline information. Response frequencies of each item were reported. Nonparametric correlations were assessed comparing the statement "In the last 12 months, I have used essential oils for myself and/or my family" with the other agree/disagree statements using Spearman's rho.

Results: A majority of participants personally used integrative medicine approaches other than aromatherapy (92.6\%) and recommended them clinically (96.8\%). Most had personally used essential oils (61\%) and wished to offer essential oil recommendations or therapies to their patients (74.0\%). Only $21.9 \%$ felt confident in their ability to counsel patients on safe use. Personal use of essential oils was highly correlated with confidence in the ability to counsel patients on safe use (Spearman coefficient 0.376, $P=0.000$ ).

Conclusions: This study indicates that clinicians interested in integrative medicine desire to provide aromatherapy recommendations, but do not feel confident in their ability to do so.
\end{abstract}

Keywords: Aromatherapy, Essential oils, United States, Physician, Nurse practitioners, Physician assistants, Integrative medicine

\section{Background}

Aromatherapy is the use of plant-derived essential oils for the purpose of supporting health and wellness. Essential oils are oil-based volatile substances usually produced by water or steam distillation, mechanical expression, or distillation. While essential oils have been used for therapeutic purposes since ancient times, relatively little research has been conducted on their clinical utility in Western medicine. Modern clinicians do not commonly receive formal training on essential oil safety and uses, and counseling on essential oils is not common among medical providers [1]. Although medical

\footnotetext{
* Correspondence: amy-pearson@uiowa.edu

${ }^{1}$ Department of Anesthesia, University of lowa Carver College of Medicine, lowa City, IA, USA

Full list of author information is available at the end of the article
}

and nursing students appear to have positive attitudes toward complementary and alternative medicine (CAM), their sources of information frequently include media sources rather than health professionals, and very little education is provided to them on CAM in their profession core curriculum [2].

Patients often do not disclose their use of integrative or alternative therapies to their clinician, and seek CAM resources outside of the exam room [3-5]. The 2017 Markets and Markets report estimates that the essential oils market value will reach $\$ 11.9$ billion by 2022 , and its compounded annual growth rate from 2017 to 2022 is estimated to be $8.83 \%$ [6]. The top 20 essential oils amount to about 104,000 tons of product [7]. The United States consumes about $40 \%$ of essential oils, and is also a major importer and exporter of them [7]. The

(c) The Author(s). 2019 Open Access This article is distributed under the terms of the Creative Commons Attribution 4.0 International License (http://creativecommons.org/licenses/by/4.0/), which permits unrestricted use, distribution, and reproduction in any medium, provided you give appropriate credit to the original author(s) and the source, provide a link to the Creative Commons license, and indicate if changes were made. The Creative Commons Public Domain Dedication waiver (http://creativecommons.org/publicdomain/zero/1.0/) applies to the data made available in this article, unless otherwise stated. 
essential oil industry has grown markedly, particularly through direct sales approaches, with major companies reporting a billion dollars in annual sales [8]. There appears to be very little clinically relevant information regarding essential oils published in reputable medical journals. A Google search of the term "essential oils" limited to the United States resulted in about 118,000,000 hits as of April 23, 2019. A PubMed search of "essential oils" and "United States" limited to humans revealed only 61 articles on the same search date.

Essential oil use by the population is widespread, yet little is known about clinicians' comfort, knowledge base, and attitudes toward essential oil use and patient counseling. While complementary and integrative therapies have been studied in the bedside nursing literature, to our knowledge, there have been no formal surveys published on the attitudes of clinical providers (e.g. physicians, advanced practice nurses, physician assistants) specifically towards aromatherapy [9].

We sought to obtain a baseline understanding of clinicians' attitudes toward essential oil use for themselves and their patients from those with an interest in Integrative Medicine attending a national conference.

\section{Methods}

The Mayo Clinic Institutional Review Board (IRB) acknowledged that the activity did not require IRB review based on submitted responses to the IRB application (\#rev20170511) and was considered exempt. Participation in the survey was voluntary, and no incentive was provided for participation. Attendees to the Mayo Clinic Updates in Integrative Medicine and Health were chosen because they came from a variety of backgrounds (type of degree, primary work facility, and specialty). Clinicians with an interest in integrative medicine were chosen as it was felt that these clinicians would be the most familiar with aromatherapy, and therefore be most likely to offer an informed opinion on its use.

An anonymous electronic survey was utilized to collect responses to questions specific to personal and professional knowledge, attitudes, and use of essential oils by those attending an Integrative Medicine conference.

\section{Study participants}

The participants in this study were clinicians attending a course entitled "Mayo Clinic Updates in Integrative Medicine and Health". Eligible participants included physicians, physician assistants, nurse practitioners and other non-prescribing providers. One hundred eighteen clinicians registered for the course. One hundred six attendees were present for the survey session, and 105 (99.1\%) took the survey. No surveys were excluded due to missing data.

\section{Study setting}

The Continuing Medical Education conference was held at a conference center in November 2017 over the course of 3 days, in which a series of didactic educational lectures and hands-on sessions were delivered throughout the day. Course topics included updates in acupuncture, nutritional supplements, massage therapy, chronic pain, mindfulness, stress \& diabetes, integrative cardiology, oncology \& women's health, lifestyle medicine, and humanities in medicine. There were no didactic lectures on aromatherapy, however the participants had the opportunity for face to face discussion with an expert and hands on experience with aromatherapy material after the survey was completed. The conference was planned and delivered by a tertiary referral medical center's staff as described previously $[10,11]$.

On the second day of the conference, the attendees were asked to complete a survey of their aromatherapy practices and opinions as well as demographic information using an electronic response system. An audience response system (ARS) was used (Turning Technologies, Youngstown, Ohio) under the direction of a study investigator (ACP) as previously described [12]. Each question was presented on individual slides projected on a main screen. Participants electronically provided their answers on the ARS devices via a lettered keypad. The results were transmitted wirelessly to a central computer and downloaded as a spreadsheet of raw data. Data were linked to individual devices, which were not assigned to specific participants.

\section{Survey design}

No previously validated surveys on aromatherapy were available for reproduction. Survey questions were therefore formulated based on author consensus and previously published studies on clinician attitudes toward complementary and alternative (CAM) or integrative medicine $[2,13-16]$. This survey has not previously been published elsewhere and can be found in the Additional file (Additional file 1: "Aromatherapy survey"). The primary goal of the questions was to gain insight on clinicians' personal knowledge, opinions, and use of essential oils and their perception of patient use of essential oils.

\section{Data collection}

Demographic data collected included age, sex, race, practice location, primary work facility, clinician specialty, clinician type, and previous training in aromatherapy. The primary outcome measure was the participant responses to survey items.

\section{Statistical analysis}

Demographic and survey data were recorded, and the response frequency to each item was analyzed. 
Nonparametric correlations were assessed comparing the statement "In the last 12 months, I have used essential oils for myself and/or my family" with the other agree/disagree statements using Spearman's rho. Twosided tests were used in all analyses, and the level of significance for all statistical tests was set at $P<0.05$. All data were entered in Microsoft Excel, and analyses were carried out using IBM SPSS Statistics for Windows (Version 21.0, Armonk, NY: IBM Corp. Released 2012). All raw data collected were submitted as Additional file 2.

\section{Results}

\section{Demographics and practice characteristics}

The demographic and practice characteristics contained in Table 1 include age, sex, race, practice location, primary work facility, clinician specialty, clinician type, and previous training in aromatherapy.

Eighty-four percent of respondents were female and $35.1 \%$ were physicians. The majority practiced in urban (27.4\%) or suburban (19.0\%) locations. Twenty-six percent worked in an academic center, and $68.1 \%$ were primary care providers. Regarding previous training in essential oils, $36.5 \%$ reported some training in aromatherapy, and none had undergone training to become a clinical aromatherapist.

\section{Aromatherapy survey results}

A majority of participants agreed with the statements "I consider essential oils to be generally safe when used appropriately" (87.2\%), "I believe that there is a need for increased clinician training in the use of essential oils" (75.5\%), "I believe that there is a need for more research on the use of essential oils" (89.5\%), "I would like to offer essential oil recommendations or therapies to my patients" (74.0\%), "In the last 12 months, I have used essential oils for myself and/or my family" (61.0\%), "In the last 12 months, I have used integrative medicine approaches other than aromatherapy for myself and/or my family" (92.6\%), and "In the last 12 months, I have recommended integrative medicine approaches other than aromatherapy in a clinical setting" (96.8\%).

A majority of participants disagreed with the statements "In the last 12 months, at least one of my patients has asked me about the use of essential oils for therapeutic purposes" (51.0\%), "I feel confident in my ability to counsel patients on the safe use of essential oils for therapeutic purposes" (78.1\%) (Table 2).

Regarding patient use of aromatherapy, participants reported that their patients who use essential oils typically used them for wellness and relaxation (20.4\%), both wellness and relaxation and treatment of disease $(48.4 \%)$ or unsure $(22.6 \%)$. No clinician reported that
Table 1 Participant characteristics, $N=105$

\begin{tabular}{|c|c|c|}
\hline Characteristics & $\begin{array}{l}\text { Total Number of } \\
\text { Participants, } n(\%)\end{array}$ & $N$ missing \\
\hline Age, years & & 9 \\
\hline $25-35$ & $27(28.1 \%)$ & \\
\hline $36-44$ & $38(39.6 \%)$ & \\
\hline $45-54$ & $11(11.5 \%)$ & \\
\hline $55-64$ & $16(16.7 \%)$ & \\
\hline$\geq 65$ & $4(4.2 \%)$ & \\
\hline Sex & & 12 \\
\hline Female & $78(83.9 \%)$ & \\
\hline Male & $14(15.0 \%)$ & \\
\hline Other & $1(1.1 \%)$ & \\
\hline Practice Location & & 10 \\
\hline Urban & $26(27.4 \%)$ & \\
\hline Suburban & $18(19.0 \%)$ & \\
\hline Small City & $30(31.6 \%)$ & \\
\hline Rural & $21(22.1 \%)$ & \\
\hline Primary Work Facility & & 13 \\
\hline Private Practice & $18(19.6 \%)$ & \\
\hline Academic Center & $24(26.1 \%)$ & \\
\hline Community Health Center & $21(22.8 \%)$ & \\
\hline Other & $29(31.52 \%)$ & \\
\hline Primary Care Provider & & 11 \\
\hline Yes & $64(68.1 \%)$ & \\
\hline No & $30(31.9 \%)$ & \\
\hline Provider type & & 11 \\
\hline $\begin{array}{l}\text { Advanced Practice Nurse or } \\
\text { Physician Assistant }\end{array}$ & $57(60.6 \%)$ & \\
\hline Physician-in-Training & $1(1.1 \%)$ & \\
\hline Physician & $32(34.0 \%)$ & \\
\hline Registered Nurse & $2(2.13 \%)$ & \\
\hline Other & $2(2.13 \%)$ & \\
\hline $\begin{array}{l}\text { Previous Education on Essential } \\
\text { Oils or Aromatherapy }\end{array}$ & & 9 \\
\hline Yes, programs for clinicians & $11(11.5 \%)$ & \\
\hline $\begin{array}{l}\text { Yes, programs for community } \\
\text { members }\end{array}$ & $24(25 \%)$ & \\
\hline No & $61(63.54 \%)$ & \\
\hline $\begin{array}{l}\text { Undergone formal training to } \\
\text { become an aromatherapist }\end{array}$ & $0(0 \%)$ & 14 \\
\hline
\end{tabular}

their patients use essential oils for treatment of disease only.

Regarding their own attitudes toward essential oil use, clinicians believed the use of essential oils may be beneficial for wellness and relaxation (28.0\%), both wellness and relaxation and disease treatment $(63.4 \%)$ or unsure 
Table 2 Survey responses

\begin{tabular}{|c|c|c|c|c|c|c|}
\hline Survey Questions & Agree & Disagree & Unsure & $\mathrm{N}$ missing & & \\
\hline $\begin{array}{l}\text { 15. In the last } 12 \text { months, at least one of my patients has } \\
\text { asked me about the use of essential oils for therapeutic } \\
\text { purposes. }\end{array}$ & 47 (49.0\%) & 49 (51.0\%) & & $9(8.6 \%)$ & & \\
\hline $\begin{array}{l}\text { 16. I feel confident in my ability to counsel patients on } \\
\text { the safe use of essential oils for therapeutic purposes. }\end{array}$ & 21 (21.9\%) & 75 (78.1\%) & & $9(8.6 \%)$ & & \\
\hline $\begin{array}{l}\text { 17. I consider essential oils to be generally safe when } \\
\text { used appropriately. }\end{array}$ & 82 (87.2\%) & $1(1.1 \%)$ & 11 (11.7\%) & $11(10.5 \%)$ & & \\
\hline $\begin{array}{l}20.1 \text { believe that there is a need for increased clinician } \\
\text { training in the use of essential oils. }\end{array}$ & 71 (75.5\%) & $6(6.4 \%)$ & $17(18.1 \%)$ & $11(10.5 \%)$ & & \\
\hline $\begin{array}{l}\text { 21. I believe that there is a need for more research } \\
\text { on the use of essential oils. }\end{array}$ & 85 (89.5\%) & $3(3.1 \%)$ & $7(7.4 \%)$ & $10(9.5 \%)$ & & \\
\hline $\begin{array}{l}22 . \text { I believe that there is a need for better reimbursement } \\
\text { for the clinical use of essential oils. }\end{array}$ & 39 (41.5\%) & $14(14.9 \%)$ & 41 (43.6\%) & $11(10.5 \%)$ & & \\
\hline $\begin{array}{l}\text { 23. I would like to offer essential oil recommendations } \\
\text { or therapies to my patients. }\end{array}$ & 71 (74.0\%) & $5(5.2 \%)$ & $20(20.8 \%)$ & 9 (8.6\%) & & \\
\hline $\begin{array}{l}\text { 24. I would like to undergo training to become certified } \\
\text { in clinical aromatherapy. }\end{array}$ & 29 (30.5\%) & 30 (31.6\%) & 36 (37.9\%) & $10(9.5 \%)$ & & \\
\hline $\begin{array}{l}\text { 25. In the last } 12 \text { months, I have used essential oils } \\
\text { for myself and/or my family. }\end{array}$ & $58(61.0 \%)$ & 37 (39.0\%) & & $10(9.5 \%)$ & & \\
\hline $\begin{array}{l}\text { 26. In the last } 12 \text { months, I have used integrative } \\
\text { medicine approaches other than aromatherapy for } \\
\text { myself and/or my family. }\end{array}$ & 87 (92.6\%) & 7 (7.45\%) & & $11(10.5 \%)$ & & \\
\hline \multirow{2}{*}{$\begin{array}{l}\text { 27. In the last } 12 \text { months, I have recommended } \\
\text { integrative medicine approaches other than } \\
\text { aromatherapy in a clinical setting. }\end{array}$} & 92 (96.8\%) & $3(3.2 \%)$ & & $10(9.5 \%)$ & & \\
\hline & $\begin{array}{l}\text { Wellness and } \\
\text { relaxation } \\
\text { purposes }\end{array}$ & $\begin{array}{l}\text { Treatment } \\
\text { of disease }\end{array}$ & $\begin{array}{l}\text { Both wellness } \\
\text { \& disease } \\
\text { treatment }\end{array}$ & $\begin{array}{l}\text { I do not have } \\
\text { patients who use } \\
\text { essential oils/Never }\end{array}$ & Unsure & Missing \\
\hline $\begin{array}{l}\text { 18. My patients who use essential oils typically use } \\
\text { them for }\end{array}$ & 19 (20.4\%) & $0(0 \%)$ & 45 (48.4\%) & $8(8.6 \%)$ & $21(22.6 \%)$ & $12(11.4 \%)$ \\
\hline $\begin{array}{l}\text { 19. I believe the use of essential oils may be } \\
\text { beneficial for }\end{array}$ & 26 (28.0\%) & $0(0 \%)$ & 59 (63.4\%) & $2(2.1 \%)$ & $6(6.5 \%)$ & $12(11.4 \%)$ \\
\hline
\end{tabular}

(6.5\%). Two percent felt that essential oil use was never beneficial.

\section{Clinicians' personal use of essential oils and aromatherapy}

Questions were asked specific to personal use of essential oils, and Table 3 contains the correlation of the responses to the statement "In the last 12 months, I have used essential oils for myself and/or my family" with the remaining binary questions of the survey. Clinician use of essential oils was positively and significantly correlated with the following statements: "In the last 12 months, at least one of my patients has asked me about the use of essential oils for therapeutic purposes", "I feel confident in my ability to counsel patients on the safe use of essential oils for therapeutic purposes", "I believe that there is a need for increased clinician training in the use of essential oils", "I believe that there is a need for more research on the use of essential oils", "I believe that there is a need for better reimbursement for the clinical use of essential oils", "I would like to offer essential oil recommendations or therapies to my patients", "I would like to undergo training to become certified in clinical aromatherapy", and "In the last 12 months, I have used integrative medicine approaches other than aromatherapy for myself and/or my family." Clinician use of essential oils and aromatherapy was not significantly correlated with the following statements: "I consider essential oils to be generally safe when used appropriately" and "In the last 12 months, I have recommended integrative medicine approaches other than aromatherapy in a clinical setting".

\section{Discussion}

In the United States, it is estimated that $62 \%$ of adults have used some form of complementary or alternative therapy in the last 12 months [17], although adult use specifically of essential oils or aromatherapy is unknown. A recent Swiss study estimated that $10.7 \%$ of patients with chronic low back pain used 
Table 3 Correlation between responses to survey questions and the use of essential oils for self or family in the previous 12 months

\begin{tabular}{lll}
\hline Survey Response & Spearman Coefficient & $P$-value \\
\hline 15. In the last 12 months, at least one of my patients has asked me about the use of essential oils for & 0.247 \\
therapeutic purposes. & 0.376 & $0.019^{*}$ \\
16. I feel confident in my ability to counsel patients on the safe use of essential oils for therapeutic purposes. & 0.162 \\
17. I consider essential oils to be generally safe when used appropriately. & 0.387 & 0.252 \\
20. I believe that there is a need for increased clinician training in the use of essential oils. & 0.639 \\
21. I believe that there is a need for more research on the use of essential oils. & 0.387 \\
22. I believe that there is a need for better reimbursement for the clinical use of essential oils. & 0.522 \\
23. I would like to offer essential oil recommendations or therapies to my patients. & 0.294 \\
24. I would like to undergo training to become certified in clinical aromatherapy. & -0.145 \\
26. In the last 12 months, I have used integrative medicine approaches other than aromatherapy for & $0.001^{*}$ \\
myself and/or my family. & $0.021^{*}$ \\
27. In the last 12 months, I have recommended integrative medicine approaches other than aromatherapy & $0.001^{*}$ \\
in a clinical setting. & $0.000^{*}$ \\
* $P<0.05$ & 0.178
\end{tabular}

aromatherapy and rated it a 4.2 out of a 10-point scale for usefulness [18]. Other studies have shown that aromatherapy may have health benefits, including relief from anxiety and depression, improved quality of life, improved sleep, and pain relief for knee osteoarthritis and renal colic [19-25].

In this study of US clinicians interested in integrative medicine, nearly all clinicians used integrative therapies for themselves and their family (92.6\%) and recommended them to patients (96.8\%). However, only $61 \%$ personally used aromatherapy for themselves or their families, and only $11.5 \%$ had any kind of clinician oriented education on essential oils. While most clinicians felt that essential oil use was generally safe and wished to offer essential oil recommendations or therapies to patients, only $21.9 \%$ felt confident in their ability to counsel patients on their safe use. A similar gap was found in a previous study, where only $15.1 \%$ of nursing students and $7.1 \%$ of medical students reported having enough knowledge about aromatherapy, while $96.3 \%$ of nursing students and $88.9 \%$ of medical students considered it useful or were undecided [2].

Personal use of essential oils was positively correlated with the belief that there is a need for increased training, research, and reimbursement regarding their use, and a desire to offer essential oil recommendations and receive formal certification in this modality. Personal use was also correlated with confidence in counseling patients as well as being approached by patients regarding aromatherapy.

This study indicates that clinicians interested in integrative medicine are being approached by patients about aromatherapy use. Clinicians desire to provide recommendations, but do not feel confident in their ability to do so. As the essential oil market continues to grow within the US and the world, clinician expertise in essential oil use may be increasingly valued by both patients and healthcare systems, and could possibly lead to safer and more evidence-based use. Healthcare systems have already begun aromatherapy programs, which include clinician education regarding the evidence for aromatherapy and essential oils, selection and properties of oils, and their safe use [26, 27]. We feel that increasing clinicians' familiarity and knowledge base, with adequate structure and support from employers and hospitals, may help to bridge this gap. At the Mayo Clinic, the authors (SC \& NR) and their colleagues developed an aromatherapy program for pediatric patients. In this model, key stakeholders were included early, and staff education and support services were implemented prior to the program's start. Essential oils were chosen based on their safety profile and were only used for inhalation. As a result, $76.7 \%$ of nurses administered aromatherapy to their patients at least monthly, and $89 \%$ rated the benefit from aromatherapy as 4 or above on a scale of $0-10$ (ten being greatest benefit) [26]. In the future, programs such as this could expand to the outpatient realm, where clinicians are given tools to offer advice on safe use of basic essential oils for certain clinical situations.

This is the first US study of clinician attitudes, practices, and beliefs regarding essential oils and aromatherapy. However, this study is limited in that it was a small study of clinicians of heterogeneous educational backgrounds, practice types, and locations. All clinicians were attending a multi-day course in Integrative Medicine, and were therefore more likely to have familiarity with and favorable opinions of integrative treatments such as aromatherapy. While most questions pertained to participants' opinions, 
questions asking objective data may have been subject to recall bias. We attempted to mitigate this by limiting recall to a finite time period (12 months). It is also possible that clinicians are not asking about or aware of their patients' use, and extent of use, of essential oils. For these reasons, we offered the "unsure" answer option for a more accurate representation.

The effect of essential oil use on the health and safety of the American public is not known, and the influence of knowledgeable clinicians on safe and appropriate use is also unknown. Future research is needed to determine the nationwide prevalence of essential oil use by patients and clinicians, and the frequency and accuracy of clinician counseling regarding aromatherapy use.

\section{Conclusions}

This study suggests that clinicians interested in integrative medicine wish to increase their aromatherapy knowledge in order to provide evidence-based guidance to their patients, but do not feel confident in their ability to do so.

\section{Additional Files}

Additional file 1: *Aromatherapy Survey *The survey as presented to the participants. (PDF $282 \mathrm{~kb}$ )

Additional file 2: *Aromatherapy Perspectives - original dataset *This is the raw dataset of the survey answers. (XLSX 34 kb)

\section{Abbreviations}

ARS: Audience Response System; CAM: Complementary \& Alternative Medicine; IRB: Institutional Review Board; US: United States

\section{Acknowledgements}

The authors would like to acknowledge Deb Bloomberg, Sairey Vitek, and Benjamin Westerling for their assistance with the conference and data collection logistics.

\section{Availability of data and material}

The raw dataset supporting the conclusions of this article have been submitted asAdditional files.

\section{Financial disclosures}

None reported.

\section{Conflict of interest}

None reported.

\section{Authors' contributions}

ASP made substantial contributions to conception and design, or acquisition of data, and interpretation of data; was involved in drafting the manuscript and revising it critically for important intellectual content; SMC made substantial contributions to conception and design and was involved in drafting the manuscript and revising it critically for important intellectual content; WMH made substantial contributions to conception and design, analysis and interpretation of data and was involved in revising it critically for important intellectual content; NJR made substantial contributions to conception and design, and was involved in revising the manuscript critically for important intellectual content; BAB made substantial contributions to conception and design, and was involved in revising the manuscript critically for important intellectual content; $A B$ made substantial contributions to conception and design, interpretation of data; and was involved in drafting the manuscript and revising it critically for important intellectual content. All authors read and approved the final manuscript.

\section{Funding}

No funding was received for this work.

Manuscript processing fees will be supported by a departmental grant.

\section{Ethics approval and consent to participate}

The Mayo Clinic Institutional Review Board (IRB) acknowledged that the activity did not require IRB review based on submitted responses to the IRB application (\#rev20170511) and was considered exempt; no further approval was required. Prior to commencement of the survey, all participants were notified by oral and written announcement that participation in the survey was voluntary and anonymous, and that there were no known risks to participation.. Participation in the survey was voluntary, and no incentive was provided for participation.

\section{Consent for publication}

Not applicable.

\section{Competing interests}

The authors report no competing interests.

\section{Author details}

${ }^{1}$ Department of Anesthesia, University of lowa Carver College of Medicine, lowa City, IA, USA. '2Department of General Internal Medicine, Mayo College of Medicine, Rochester, MN, USA. ${ }^{3}$ Department of Anesthesiology \& Perioperative Medicine, Mayo College of Medicine, Rochester, MN, USA. ${ }^{4}$ Department of General Internal Medicine, Mayo College of Medicine, Rochester, MN, USA.

Received: 31 December 2018 Accepted: 23 June 2019

Published online: 12 July 2019

\section{References}

1. Maddocks-Jennings W, Wilkinson JM. Aromatherapy practice in nursing: literature review. J Adv Nurs. 2004;48(1):93-103.

2. Yildirim Y, Parlar S, Eyigor S, Sertoz OO, Eyigor C, Fadiloglu C, et al. An analysis of nursing and medical students' attitudes towards and knowledge of complementary and alternative medicine (CAM). J Clin Nurs. 2010;19(7-8):1157-66.

3. Galicia-Connolly E, Adams D, Bateman J, Dagenais S, Clifford T, Baydala L, et al. CAM use in pediatric neurology: an exploration of concurrent use with conventional medicine. PLoS One. 2014:9(4):e94078.

4. Misra SM, Guffey D, Roth I, Giardino AP. Complementary and alternative medicine use in uninsured children in Texas. Clin Pediatr (Phila). 2017;56(9):866-9.

5. Shakeel M, Little SA, Bruce J, Ah-See KW. Use of complementary and alternative medicine in pediatric otolaryngology patients attending a tertiary hospital in the UK. Int J Pediatr Otorhinolaryngol. 2007;71(11): 1725-30.

6. marketsandmarkets.com. Essential Oils Market by Product Type (Orange, Lemon, Lime, Peppermint, Citronella, Jasmine), Method of Extraction, Application (Food \& Beverage, Cosmetics \& Toiletries, Aromatherapy, Home Care, Health Care), and Region - Global Forecast to 20222017 [updated June 2017. Report code FB 5385:[Available from: https://www.marketsandmarkets.com/Market-Reports/essential-oilmarket-119674487.html.

7. Devi MP, Chakrabarty S, Ghosh SK, Bhowmick N. Essential oil: its economic aspect, extraction, importance, uses, hazards and quality. In: Sharangi AB Datta S, editors. Value addition of horticultural crops: recent trends and future directions. New Delhi: Springer India; 2015. p. 269-78.

8. Monroe R. How essential oils became the cure for our age of anxiety. The new Yorker [Internet]. 2017 October 31, 2018; (October 9, 2017). Available from: https://www.newyorker.com/magazine/2017/10/09/how-essential-oilsbecame-the-cure-for-our-age-of-anxiety

9. Boesl R, Saarinen $H$. Essential oil education for health care providers. Integr Med (Encinitas). 2016;15(6):38-40.

10. Hooten WM, Bruce BK. Beliefs and attitudes about prescribing opioids among healthcare providers seeking continuing medical education. J Opioid Manag. 2011;7(6):417-24. 
11. Pearson AC, Eldrige JS, Moeschler SM, Hooten WM. Opioids for chronic pain: a knowledge assessment of nonpain specialty providers. J Pain Res. 2016;9:129-35.

12. Pearson AC, Moman RN, Moeschler SM, Eldrige JS, Hooten WM. Provider confidence in opioid prescribing and chronic pain management: results of the opioid therapy provider survey. J Pain Res. 2017;10:1395-400.

13. Abbott RB, Hui KK, Hays RD, Mandel J, Goldstein M, Winegarden B, et al. Medical student attitudes toward complementary, alternative and integrative medicine. Evid Based Complement Alternat Med. 2011; 2011:985243.

14. Kanadiya MK, Klein G, Shubrook JH Jr. Use of and attitudes toward complementary and alternative medicine among osteopathic medical students. J Am Osteopath Assoc. 2012;112(7):437-46.

15. Lie D, Boker J. Development and validation of the CAM health belief questionnaire (CHBQ) and CAM use and attitudes amongst medical students. BMC Med Educ. 2004;4(2).

16. Freymann H, Rennie T, Bates I, Nebel S, Heinrich M. Knowledge and use of complementary and alternative medicine among British undergraduate pharmacy students. Pharm World Sci. 2006;28(1):13-8.

17. Barnes PM, Powell-Griner E, McFann K, Nahin RL. Complementary and alternative medicine use among adults: United States, 2002. Adv Data. 2004:(343):1-19.

18. Dubois J, Scala E, Faouzi M, Decosterd I, Burnand B, Rodondi PY. Chronic low back pain patients' use of, level of knowledge of and perceived benefits of complementary medicine: a cross-sectional study at an academic pain center. BMC Complement Altern Med. 2017;17(1):193.

19. Sanchez-Vidana DI, Ngai SP, He W, Chow JK, Lau BW, Tsang HW. The effectiveness of aromatherapy for depressive symptoms: a systematic review. Evid Based Complement Alternat Med 2017;2017:5869315.

20. Press-Sandler O, Freud T, Volkov I, Peleg R, Press Y. Aromatherapy for the treatment of patients with behavioral and psychological symptoms of dementia: a descriptive analysis of RCTs. J Altern Complement Med. 2016:22(6):422-8.

21. Nasiri A, Mahmodi MA, Nobakht Z. Effect of aromatherapy massage with lavender essential oil on pain in patients with osteoarthritis of the knee: a randomized controlled clinical trial. Complement Ther Clin Pract. 2016;25:75-80.

22. Lakhan SE, Sheafer H, Tepper D. The effectiveness of aromatherapy in reducing pain: a systematic review and meta-analysis. Pain Res Treat 2016; 2016:8158693.

23. Irmak Sapmaz H, Uysal M, Tas U, Esen M, Barut M, Somuk BT, et al. The effect of lavender oil in patients with renal colic: a prospective controlled study using objective and subjective outcome measurements. J Altern Complement Med. 2015;21(10):617-22.

24. Hwang $\mathrm{E}$, Shin $\mathrm{S}$. The effects of aromatherapy on sleep improvement: a systematic literature review and meta-analysis. J Altern Complement Med. 2015;21 (2):61-8.

25. Bystritsky A, Hovav S, Sherbourne C, Stein MB, Rose RD, Campbell-Sills L, et al. Use of complementary and alternative medicine in a large sample of anxiety patients. Psychosomatics. 2012;53(3):266-72.

26. Conlon PM, Haack KM, Rodgers NJ, Dion L, Cambern KL, Rohlik GM, et al. Introducing essential oils into pediatric and other practices at an Academic Medical Center. J Holist Nurs. 2017;35(4):389-96.

27. Joswiak D, Kinney ME, Johnson JR, Kolste AK, Griffin KH, Rivard RL, et al. Development of a health system-based nurse-delivered aromatherapy program. J Nurs Adm. 2016:46(4):221-5.

\section{Publisher's Note}

Springer Nature remains neutral with regard to jurisdictional claims in published maps and institutional affiliations.

Ready to submit your research? Choose BMC and benefit from:

- fast, convenient online submission

- thorough peer review by experienced researchers in your field

- rapid publication on acceptance

- support for research data, including large and complex data types

- gold Open Access which fosters wider collaboration and increased citations

- maximum visibility for your research: over $100 \mathrm{M}$ website views per year

At BMC, research is always in progress.

Learn more biomedcentral.com/submissions 